\title{
ANALISIS PENCATATAN AKUNTANSI PADA DANA BANTUAN OPERASIONAL SEKOLAH (BOS) (STUDI KASUS DI SMK NEGERI 1 LUNYUK)
}

\author{
Analysis Of Accounting Listing On Funds Assistance Of School Operations (Bos) (Case \\ Study In 1 Vocational High School Of Lunyuk)
}

\author{
Wardah Ges Alamudy ${ }^{1}$ \\ ${ }^{1}$ Program Studi Akuntansi, Fakultas Ekonomi dan Bisnis, Universitas Tekonologi Sumbawa \\ *) E-mail : wrwardah.ww@gmail.com
}

\begin{abstract}
This study aims to analyze the accounting recording process carried out by SMK Negeri 1 lunyuk and to find out whether the recording of School Operational Assistance (BOS) funds at SMK Negeri 1 lunyuk is in accordance with BOS technical guidelines in 2016. This research is descriptive research using a qualitative approach. Methods of data collection through the interview and documentation process, the subject of the study were the principal, treasurer, and the BOS team then the data obtained were analyzed using qualitative descriptive methods. The results of this study indicate that the process of recording School Operational Assistance (BOS) funds conducted by State Junior High School 1 lunyuk has not been compiled in accordance with BOS Technical Guidance in 2016 as should be arranged in the recommended format for RKAS, bookkeeping, realization of the use of funds for each funding source, realsation recapitulation use of BOS SMK funds, cash receipts and minutes of cash checks, proof of expenses, reporting. According to the results of the study authors that SMK Negeri 1 Lunyuk only follow accountability reports with the format of the realization of the use of funds for each source of funds, recalculation of the use of BOS SMK funds, cash receipts and minutes of cash checks, proof of expenditure and not attach physical evidence of activities that have been do it.
\end{abstract}

Keywords: Accounting Records, School Operational Assistance Fund, SMK Negeri 1 Lunyuk

\begin{abstract}
ABSTRAK
Penelitian ini bertujuan untuk menganalisis proses pencatatan akuntasi yang dilakukan oleh SMK Negeri 1 lunyuk dan untuk mengetahui apakah pencatatan dana Bantuan Operasional Sekolah (BOS) di SMK Negeri 1 lunyuk sudah sesuai dengan juknis BOS Smk tahun 2016. Penelitian ini merupakan penelitian deskriftif dengan menggunakan pendekatan kualitatif. Metode pengumpulan data melalui proses wawancara dan dokumentasi, subjek penelitian adalah kepala sekolah, bendahara, dan tim BOS kemudian data yang didapatakan dianalisis menggunakan metode deskriftif kualitatif. Hasil penelitian ini menunjukan proses pencatatan dana Bantuan Operasional Sekolah (BOS) yang dilakukan oleh Smk Negeri 1 lunyuk belum disusun sesuai dengan Juknis BOS Smk 2016 seperti yang seharusnya tersusun dalam format yang dianjurkan untuk RKAS, pembukuan, realisasi penggunaan dana tiap sumber dana, rekapitulasi realsasi penggunaan dana BOS SMK, opname kas dan berita acara pemeriksaan kas, bukti pengeluaran, pelaporan. Menurut hasil penelitian penulis bahwa SMK Negeri 1 Lunyuk hanya menyusus laporan pertanggungjawaban dengan format realisasi penggunaan dana tiap sumber dana, rekapitulasi realsasi penggunaan dana BOS SMK, opname kas dan berita acara pemeriksaan kas, bukti pengeluaran serta tidak melampirkan bukti-bukti fisik kegiatan yang telah di laksanakan.
\end{abstract}

Kata kunci: Pencatatan Akuntansi, Dana Bantuan Operasional Sekolah, SMK Negeri 1 Lunyuk.

\section{Pendahuluan}

Pendidikan merupakan hal yang sangat penting dalam kehidupan untuk meningkatkan mutu sumber daya manusia suatu negara. Negara yang hebat adalah Negara yang peduli akan pendidikan rakyatnya. Setiap negara memiliki tujuan serta target keterlaksanaan pendidikan. Di Indonesia, menurut Pasal 3 Undang-Undang nomor 20 tahun 2003, tujuan pendidikan nasional adalah untuk mengembangkan potensi peserta didik agar menjadi manusia yang beriman dan bertaqwa kepada tuhan yang maha Esa, berakhlak mulia, sehat, berilmu, cakap, kreatif, mandiri, dan menjadi warga negara yang demokratis serta ber- tanggung jawab.

Untuk mencapai tujuan pendidikan suatu bangsa, ada negara yang ber- peran dalam penyediaan sarana pendidikan. Menurut Undang-Undang Re- publik Indonesia Nomor 20 tahun 2003 tentang sistem pendidikan Nasional menyebutkan bahwa pemerintah dae- rah wajib memberikan layanan dan kemudahan, serta menjamin terseleng- garanya pendidikan yang bermutu bagi setiap warga negara tanpa diskriminasi.

Salah satu peran pemerintah adalah meringankan biaya pendidikan di Indonesia, dalam hal ini Kementerian Pendidikan dan Budaya memberi dana Bantuan Operasional Sekolah (BOS). Program BOS yang disalurkan sejak bulan Juli 2005, sangat berperan dalam mencapai tujuan pendidikan. Dalam mengelola dana Bantuan Operasional Sekolah (BOS), dana diterima oleh sekolah seutuhnya lalu mengelola secara mandiri dengan bantuan guru dan komite sekolah. Dengan demikian, dana BOS sangat mendukung imple- mentasi penerapan manajemen berbasis sekolah, bertujuan untuk memberdayakan sekolah melalui pemberian kewenangan.

Melalui peraturan Menteri Pendidikan dan Kebudayaan Repulik Indonesia nomor 80 tahun 2013 mengatakan agar direktorat pembinaan Sekolah Menengah Kejuruan (SMK) 
menjadikan pendidikan menengah universal sebagai pijakan kebijakan untuk menyediakan layanan pendidikan di SMK agar tercapai kualitas serta kesejahter- aan bagi layanan pendidikan menengah untuk masyarakat. Besaran dana BOS SMK yang diterima sekolah dihitung berdasarkan jumlah siswa masing- masing sekolah dan satuan biaya (unit cost) bantuan.

Alokasi dana yang besar membu- tuhkan pengelolaan dan pertanggung- jawaban yang transparan dari pihak sekolah. Hal ini dimaksudkan agar penggunaan dana BOS sesuai dengan petunjuk penggunaan teknis yang telah diatur oleh Kementrian Pendidikan. Penyimpangan anggaran dana alokasi khusus atau biaya operasional sekolah (BOS) disebabkan oleh adanya pelanggaran regulasi. Pelanggaran ini dilakukan oleh beberapa pemerintah daerah dan sekolah penerima dana.

Menurut penulis penyimpangan dana operasional sekolah ini terjadi bukan hanya karena ada niat tapi kare- na kesempatan dan kurangnya ketegasan dari pihak pengawas penggunaan Dana Operasional Sekolah (BOS) ditambah kurang profesional pihak-pihak sekolah dalam menjalan- kan amanat pemerintah untuk menyejahterakan dunia pendidikan, namun tidak semua sekolah melakukan pelanggaran seperti penelitian yang dilakukan di SMK Negeri 1 Yogyakarta.

Berdasarkaan hasil wawancaran permasalahan yang didentifikasi oleh penulis pada SMK Negeri 1 Lunyuk bahwa dana bantuan operasional sekolah tahun 2015 diduga terjadi penyimpangan. Dana semester I senilai Rp 67,2 juta yang sudah dicairkan, namun tidak digunakan sebagaimana mestinya. Masalah lain terkait mengenai transparansi pelaporan pertanggung jawaban dana BOS oleh SMK negeri 1 Lunyuk tidak terdapat lampiran foto-foto fisik bukti pembelian barang mau- pun bangunan kecil yang dibuat, Kepala Sekolah SMK Negeri 1 Lunyuk mengaku bahwa masih kesusahan dalam membuat laporan pertanggungjawaban terhadap dana BOS yang diberikan pemerintah itu karena tidak ada satupun guru atau staf yang berlatar belakang pendidikan akuntansi.

Penyelewengan dana dapat dipantau melalui pencatatan akuntansi yang benar, maka dari itu setiap sekolah yang menerima dana Bantuan Operasional Sekolah (BOS) wajib melakukan pencatatan pertanggungja- waban atas dana yang diterima. Pencatatan dan pelaporan pertanggungja- waban merupakan komponen penting dalam menjalankan organisasi (Monika, 2012).

\section{Metode}

\section{Jenis Penelitian}

Jenis penelitian ini adalah Penelitian Deskriptif kualitatif. Penelitian Deskriptif adalah penelitian yang memaparkan dan bertujuan memberikan gambaran serta menjelaskan dari variabel yang diteliti.

\section{Lokasi dan Waktu}

Penelitian dilakukan di SMK Negeri 1 Lunyuk yang beralamat di J1 litas Sum- bawa - lunyuk Km 93 Lunyuk. Penelitian ini akan dilaksanakan pada bulan januari 2018 sampai februari 2018.

\section{Proses Pengumpulan Data}

Ada tiga proses kegiatan yang di lakukan oleh peneliti dalam rangka pengumpulan data. Adapun proses yang dimaksud, yaitu :
Proses Memasuki Lokasi penelitian, Dalam tahap ini peneliti me- masuki lokasi dengan membawa izin penelitian dan menemui pimpinan tempat dilakukan penelitian, selanjutnya peneliti mengungkapkan maksud dan tujuan sekaligus meminta izin untuk melakukan penelitian. Peneliti ju- ga melakukan interaksi terhadap peg- awainya untuk membina hubungan baik sehingga dapat mengurangi jarak sosial antara peneliti dan sumber data.

Ketika Berada di Lokasi Penelitian, dimana dalam tahap ini peneliti menjalin hubungan pribadi dalam subjek penelitian. Peneliti mencari in- formasi yang dibutuhkan, mengada- kan pengamatan dan menangkap makna dari fenomena yang ditelusuri. Kemudian informasi yang di dapat- kan oleh peneliti, diolah dan ditafsir- kan setelah itu di analisis. Dengan demikian informasi selengkap- lengkapnya dapat di peroleh sesuai dengan fokus penelitian.

Mengumpulkan data, untuk mendapatkan data-data yang di perlukan dilakukan dengan melakukan wawancara dan dokumentasi. Wawancara merupakan proses pengumpulan data dengan memberikan pertanyaan secara lisan kepada orang-orang yang bersangkutan dengan objek yang di teliti. Penulis melakukan wawancara kepada kepala sekolah, bendahara serta guru-guru SMK Negeri 1 lunyuk. Dokumentasi merupakan proses pengumpulan data berupa dokumen- dokumen bukti. Dokumen yang dikumpulkan oleh penulis adalah laporan pertanggungjawaban penggunaan dana bantuan operasional sekolah selama tahun 2016.

\section{Data dan Sumber Data}

Data primer adalah data yang diperoleh langsung dari responden atau ada hubungannya dengan objek melalui tanya jawab atau wawancara dengan kepala sekolah, bendahara, guru-guru tim BOS sesuai dengan fokus penelitian yang penulis teliti.

\section{Teknik Analisis Data}

Metode analisis data yang digunakan dalam penelitian ini ada- lah deskriptif kualitatif dengan melakukan pendekatan dengan metode analisis data kualitatif model interaktif dari Miles dan Huberman dalam Satori dan Komariah (2010:39) yang mencakup pengum- pulan data, reduksi data, penyajian data, dan penarikan kesimpulan/verifikasi.

\section{Hasil Dan Pembahasan}

\section{Analisis Pencatatan Akuntansi}

Pencatatan akuntansi adalah meli- puti laporan pertanggungjawaban, tingkat transparansi, akuntabelitas, efektif dan efisiensi. Aturan yang dikeluarkan menteri pendidikan dan kebudayaan semakin spesifik. Hal ini bertujuan agar meminimalisir kesala- han yang akan terjadi dalam pelaporan serta penggunaan dana Bantuan Operasional Sekolah (BOS).

Pada buku petunjuk bos tahun 2016 sudah dijelasankan tentang komponen- komponen yang harus di biayai dan komponen larangan pembiayaan oleh dana batuan operasional sekolah (BOS). Ada tujuh belas komponen yang harus dipenuhi oleh dana bos SMK pengadaan buku pembelajaran/buku pedoman penunjang pembelajaran, pembiayaan pengelolaan satuan pendidikan, pengadaan alat habis pakai praktikum, pengadaan bahan habis pakai praktikum, langganan daya dan jasa, penyelenggaraan evaluasi belajar, penyelenggaraan kegiatan siswa/ekstrakulikuler, pemeliharaan praserana, kegiatan penerimaan peserta didik baru, penyelenggaraan kegiatan uji kompetensi dan sertifikat kejuruan, pengadaan praktek kerja industri, pengembangaan sekolah rujukan, pengelolaan 
layanan sekolah berbasis TIK, biaya asuransi keamanan dan keselamatan pendidikan serta pe- nanggulangi bencana, pembeliaan peralatan komputer pembelajaran, biaya penyusunan dan peloporan.

Selain komponen yang harus dibiayai dan bukan komponen pembiayaan di dalam Juknis BOS SMK 2016 terdapat format form yang harus di gunakan untuk laporan pertanggungjawaban agar mempermudah pihak sekolah dalam melaporkan penggunaan dana Bantuan Operasional Sekolah yang diberikan pada masing sekolah menengah kejuruan. Namun SMK Negeri 1 lunyuk belum menerapkan secara sempurna sesuai yang ditetapkan dalam Juknis yang dikeluarkan oleh menteri pendidikan dan ke- budayaan republik Indonesia. Hal tersebut ditunjukan dengan penyususnan laporan pertanggungjawaban yang dilakukan SMK Negeri 1 lunyuk belum lengkap, Format penyusunan yang dikerjakan oleh SMK Negeri 1 lunyuk Pembukuan,Realisasi penggunaan dana tiap sumber dana, Rekapitulasi realisasi penggunaan dana BOS SMK, Opname kas dan berita acara pemeriksan kas, Bukti pengeluaran, dan Pelaporan sedangkan yang harus dikerjakan adalah penyusunan RKAS, Pembukuan, Realisasi penggunaan dana tiap sumber dana, Rekapitulasi realisasi penggunaan dana BOS SMK, Opname kas dan berita acara pemeriksan kas, Bukti pengeluaran, dan Pelaporan dan seiap komponen di dalamanya harus lengkap. Berikut adalah penjelasan melalui tabel tentang ketidak sesuaian laporan pertanggungjawaban yang di susun oleh pihak SMK Negeri 1 lunyuk dengan form yang diterapkan menurut Juknis:

Tabel 1. Format dalam Pengelolaam dana BOS

\begin{tabular}{|c|c|c|c|}
\hline \multirow{2}{*}{ Susunan Juknis Bos } & \multicolumn{3}{|c|}{ Diterapkan Disekolah } \\
\hline & Sudah & Belum & Belum \\
\hline RKAS & & $\mathrm{V}$ & \\
\hline Pembukuan & & & $\mathrm{V}$ \\
\hline Realisasi penggunaan dana tiap sumber dana & $\mathrm{V}$ & & \\
\hline Rekapitulasi realisasi penggunaan dana BOS SMK & $\mathrm{V}$ & & \\
\hline Opname kas dan berita acara pemeriksan kas. & $\mathrm{V}$ & & \\
\hline Bukti pengeluaran & $\mathrm{V}$ & & \\
\hline Pelaporan & & & $\mathrm{V}$ \\
\hline
\end{tabular}

\section{Analisis Terhadap Laporan Pertanggungjawaban}

Pencatatan laporan pertanggungjawaban dana Bantuan Operasional Sekolah (BOS) SMK Negeri 1 lunyuk hanya memiliki format yang disusun RAB, pertanggungjawaban dana, format rekapitulasi, buku kas umum, buku pembantu pajak dan kumpulan bukti- bukti pengeluaran yang berupa kwitansi dan surat setor pajak.

"Menurut hasil wawancara dengan kepala sekolah dan bendahara SMK Negeri 1 lunyuk, Susunan laporan pertanggungjawaban yang tidak sesuai dengan format yang ditetapkan oleh Juknis disebabkan kurangnya tenaga ahli dalam membuat laporan, serta kurang kerj a sama antara pihak guru dalam menyusun laporan pertanggungjawaban, dan pembuatan laporan yang buruh- buruh membuat kurang maksimal dalam penyusunan lapoaran. Namun untuk susunan bukti-bukti pengeluaran seperti kwitansi dan surat setor pajak sudah rapi menggunakan nomor bukti serta tanggal yang lengkap.

\section{Rencana Kegiatan dan Anggaran Sekolah (RKAS)}

Untuk laporan Rencana Kegiatan dan Anggaran Sekolah dibuat setahun sekali pada tahun pelajaran yang ditandatangani oleh kepala sekolah, komite sekolah dan khusus sekolah swasta ditambah ketua yayasan. Namun Smk negeri 1 lunyuk belum pernah membuat laporan Rencana Kegiatan dan Anggaran sekolah selama tahun ajaran 2016 hal ini di akui oleh bendahara dan kepala sekolah Smkn 1 lunyuk karena keterbatasan tenaga dan waktu dalam membuat laporan seperti yang di paparkan oleh bapak I wayan sabeh, SP. "Bahwa sekolah kami tidak memiliki tenaga yang berlatar belakang akuntansi dan sangat keterbatasan waktu untuk menyelsaikan karena laporan disusun diwaktu mendekati dateline".

\section{Pembukuan}

Sekolah diwajibkan membuat pembukuan dari dana yang diperoleh sekolah untuk program BOS SMK. Pembukuan yang digunakan dapat dengan tulis tangan atau menggunakan komputer. Buku yang digunakan adalah Buku Kas Umum, Buku Pembantu Kas, Buku Pembantu Bank, Buku Pembantu Pajak.

Untuk Buku Kas Umum Smkn 1 lunyuk sudah membuat dengan lengkap sesuai dengan format dalam Juknis BOS SMK hanya saja menurut pengakuan dari bapak Adi irawansyah, ST. " Bahwa waktu penyusunan di lakukan terburu- buru mengejar waktu pelaporan tetapi dicatat berdasarkan bukti-bukti transaksi yang disimpan".

Untuk penyusunan Buku Pembantu Kas dan Buku Pembantu Bank belum pernah dilakukan sepanjang tahun ajaran 2016, berbeda dengan Buku Pembantu Pajak sudah disusun rapi sesuai dengan transaksi yang ada pada Buku Kas Umum dan bukti transaksi.

\section{Realisasi penggunaan dana tiap sumber dana (Formulir BOS-K7)}

Laporan ini disusun berdasarkan Buku Kas Umum (Formulir BOS- K3) dari semua sumber dana yang dikelola sekolah pada periode yang sama. Laporan ini dibuat triwulanan dan ditandatangani oleh bendahara, kepala sekolah dan komite sekolah.

Laporan ini harus dilengkapi dengan surat pernyataan tanggung jawab yang menyatakan bahwa dana BOS SMK yang diterima telah digunakan sesuai NPH BOS SMK yang tercantum dalam Permendagri tentang Pengelolaan BOS SMK. Bukti pengeluaranyang sah disim- pan dan dipergunakan oleh peneri- ma hibah selaku obyek pemeriksaan.

Menurut hasil wawancara dengan bapak kepala sekolah dan bendahara Smkn 1 lunyuk "bahwa laporan realisasi penggunaan telah di buat dan diserahakan tetapi tidak persis sama dengan format yang di tentukan pada Juknis BOS SMK 2016 juga tidak memiliki lampiran NPH (Naskah Perjanjian Hibah) BOS SMK seperti yang ada dalam Juknis". Laporan 
realisasi yang disusun sudah dilengkapi tandatangan kepala sekolah, bendahara dan ketua komite.

\section{Rekapitulasi Realisasi Penggunaan Dana BOS SMK} (Formulir BOS- K7a)

Laporan ini merupakan rekapitu- lasi dari 17 komponen penggunaan dana BOS SMK dan disusun ber- dasarkan Formulir BOS-K7. Laporan ini dibuat triwulanan dan ditandatangani oleh bendahara, kepala sekolah dan komite sekolah. Laporan rekapitulasi realisasi penggunaan dana BOS setiap triwulan di Smkn 1 lunyuk sepanjang tahun 2016 sudah disusun rapi sesuai format yang ditentukan dalam Juknis BOS.

\section{Opname kas (formulir BOS-K7c)}

Setiap bulan Buku Kas Umum (BKU) ditutup dan ditandatangani oleh kepala sekolah dan bendahara/pemegang kas. Sebelum pe- nutupan BKU, Kepala sekolah melakukan opname kas dengan menghitung jumlah kas baik yang ada di sekolah (kas tunai) maupun kas yang ada di bank (buku ta- bungan sekolah). Hasil dari opname kas kemudian dibandingkan dengan saldo akhir BKU pada bulan ber- sangkutan. Apabila terjadi perbe- daan, maka harus dijelaskan penyebab perbedaannya. Pada Smkn 1 lunyuk opname kas sudah dilakukan kebetulan hasil dari setiap triwulan adalah nihil jadi tidak ada perbandingan yang bisa dilakukan atau yang menjadi masalah kerena setiap uang yang diterima habis digunakan untuk kebutuhan sekolah selama triwulan masing-masing. Menurut pendapat kepala sekolah dan bendahara kami mencatta apa adanya sesuai keadaan sebenarnya dan semampu kami sejauh ini tidak terjadi masalah.

\section{Bukti Pengeluaran}

Setiap transaksi pengeluaran harus didukung dengan bukti kuitansi yang sah;

Bukti pengeluaran uang dalam jumlah tertentu harus dibubuhi materai yang cukup sesuai dengan ke- tentuan bea materai. Untuk transaksi dengan nilai sampai Rp 250.000,tidak dikenai bea meterai, sedang transaksi dengan nilai nominal antara $\mathrm{Rp} 250.000$,- sampai dengan Rp. 1.000,dikenai bea meterai dengan tarif sebesar $\mathrm{Rp} 3.000$,- dan transaksi dengan nilai nominal lebih besar Rp 1.000.000,dikenai bea meterai dengan tarif sebesar Rp 6.000,-

Uraian pembayaran dalam kuitansi harus jelas dan terinci sesuai dengan peruntukannya; Uraian tentang jenis barang/jasa yang dibayar dapat dipisah dalam bentuk faktur sebagai lampiran kui- tansi; Setiap bukti pembayaran harus di setujui Kepala Sekolah dan lunas dibayar oleh Bendahara; Segala jenis bukti pengeluaran harus disimpan oleh bendahara BOS SMK sekolah sebagai bahan bukti dan bahan laporan.

Dari susunan diatas Smkn 1 lunyuk telah menyusun dengan rapi sesuai poin-poin diatas dengan format yang sangat rapi. Bukti-bukti faktur dan kwitansi sudah disediakan oleh bendahara Smkn 1 lunyuk pada saat penutupan buku kas pihak ketiga hanya menandatangani dan membumbui cap stempel.

\section{Pelaporan}

Pelaporan penggunan dana BOS SMK Negeri 1 lunyuk sudah disusun dengan rapi hanya masih ada beberapa komponen yang belum lengkap yaitu pembukuan dan pelaporan ada pula beberapa komponen yang belum ada yaitu RKAS dan ada juga komponen yang sudah lengkap dan telah disusun dengan rapi yaitu realisasi penggunaan dana tiap sumber dana, rekapitulasi realisasi penggunaan dana Bantuan Operasional Sekolah (BOS) SMK, opname kas dan berita acara pemeriksa kas, dan bukti pengeluaran. Mengenai beberapa kekurangan dalam penyusunan menurut pengakuan kepala sekolah hal ini terjadi kerena keterbatasan kemampuan dan waktu dalam penyusunan.

\section{Simpulan}

Proses pencatatan dana Bantuan Operasional Sekolah (BOS) yang dilakukan oleh Smk Negeri 1 lunyuk belum disusun sesuai dengan Juknis BOS SMK 2016 seperti yang seharusnya tersusun dalam format yang dianjurkan untuk RKAS, pembukuan, realisasi penggunaan dana tiap sumber dana, rekapitulasi realsasi penggunaan dana BOS SMK, opname kas dan berita acara pemeriksaan kas, bukti pengeluaran, pelaporan. Menurut hasil penelitian penulis bahwa SMK Negeri 1 Lunyuk hanya menyusus laporan pertanggungjawaban dengan format realisasi penggunaan dana tiap sumber dana, rekapitulasi realsasi penggunaan dana BOS SMK, opname kas dan berita acara pemeriksaan kas, bukti pengeluaran serta tidak melampirkan bukti-bukti fisik kegiatan yang telah di laksanakan.

\section{Daftar Pustaka}

Akbar, Muhammad Firyal "Evaluasi Ke- bijakan Program Pemberian Dana Bantuan Operasional Sekolah" Jurnal Analisis Dan Pelayanan Publik Volume 2, Nomor 1, Juni 2016.

Aan Komariah \& Djam'an Satori (2010). Metode Penelitian Kualitatif. Bandung : Alfabeta.

Anshori, Muslich \& Sri Iswati. 2006. BUKU AJAR : Metodelogi Penelitian Kuantitatif. Surabaya: Airlangga University Press.

Hetti F Manurung \& Achmad Hidir (2013). “ Pelaksanaan Program Bantuan Operasional Sekolah (BOS)”. Jurnal Kebijakan Public, Volume 4, Nomor 2, Oktober 2013 Hala- man 119-218.

Hidayat, Moch, Faisal, (2016). "Pengel- olahan Dana Bantuan Operasional Sekolah (BOS) Untuk Kegiatan Ekstrakulikuler Di Mi Sultan Agung Sulaiman Yogyakarta” Skripsi Yogyakarta.

Http ://Kemendikbud.Go.Id ,Diakses 4 November 2017.

Jayatri, Monika.(2012)"Analisis Pengelolaan Dana Bantuan Operasional Sekolah (BOS) Di SMPN 11 Yogyakarta Dan SMP 1 Purwarejo". Skripsi Fakultas Ekonomi Pada Universitas Indonesia Depok.

Juknis BOS SMK. 2016 "Petunjuk Teknis Penggunaan Dan Pertanggungjawaban Keuangan Dana Bantuan Operasional Sekolah Menengah Kejuruan”.

Kusumo, Wahyudi \& Masluyah Suib. 2014 “ Pengelolaan Dana Bantuan Operasional Sekolah (BOS) Disekolah Negeri”.

Margono S. Drs. 2007. "Metedologi Penelitian Pendidikan Komponen MKDK. Rineka cipta : Jakarta.

Modul Akuntansi Dan Peloporan Pen- erimaan Dan Pengeluaran Daerah Yang Tidak Melalui Rekening Kas Umum Daerah (Rkud). Halaman 28-41.

Muhammad, Hamid. (2016) "Penyimpangan Dana Bos Terjadi Karena Pelanggaran Regulasi”.

(Https//Googleweblight.Com. Di- akses 5 Desember 2017). 
Munawir S. (2002). Analisis Laporan Keuangan. Yogyakarta: Liberty. Halaman 15. Peraturan Pemerintah Nomor 48 Tahun 2008

Ramadhansyah, Muhammad. (2013).“ Pengaruh Dana Bantuan Operasional Sekolah (BOS) Ter- hadap Optimalisasi Proses Belanja Mengajar Pada Tingkat Sekolah Menengah Pertama Di Kota Samarida”. Jurnal Ilmu Pemerintahan.

Republik Indonesia. (2003) Peraturan Men- teri Pendidikan Dan Kebudayaan Nomor 80 Tahun 2003 Tentang Pendidikan Menengah Universal.

Riduwan. 2004. “Metode Riset” jakarta : Rineka cipta.

Solikhatun, Ismi. (2016). "Analisis Pengelolaan Dana Bantuan Operasional Sekolah (BOS)Studi Di SMK Negeri 1 Yogyakarta". Jurnal Kajian Pendidikan Akuntansi Indonesia Edisi 5 Tahun 2016.

Sugiyano. 2009. Metode Penelitian Kuanti- tatif Kualitatif
Dan R \& D, Bandung : Alphabet.

Sulfiati F, (juli,2010) “Akuntabilitas Pengelolaan Dana Bantuan Operasional Sekolah (BOS) Da- lam Penyelenggaraan Pendidikan Dikabupaten Sinjai". Jurnal Ilmu Pemerintahan Volume 3, Nomor 2. Diakses 13 Desember 2017.

Susanti, (2017). "Prinsip Pengelolaan Dana Bantuan Operasional Sekolah (BOS) Di SMK Negeri 5 Samarinda". Jurnal Administrasi Negara, Volume 5, Nomor 32017.

Tauziry, Yusuf, (juni, 2016) "Polisi Kan- tongi Dua Calon Tersangka BOS Smkn 1 Lunyuk". Suara NTB. Diakses 2 Novembeer 2017.

Undang-undang Nomor 20 Tahun 2013 Tentang System Pendidikan Nasional. 